\title{
The impact of soil suction variation on earthquake intensity indices
}

\author{
Mahnoosh Biglari ${ }^{1}$, a , Farshad Fouladi ${ }^{2}$ and Iman Ashayeri ${ }^{1}$ \\ ${ }^{1}$ Assistant Professor, Razi University, Kermanshah, Iran \\ ${ }^{2}$ Graduate student, Razi University, Kermanshah, Iran
}

\begin{abstract}
Soil properties can completely change the ground motion characteristics as they travel from the bedrock to the surface because, soil as a low-pass filter, may amplify or deamplify seismic motions in some frequencies on the wave travelling path. Recent studies about the advanced unsaturated soil mechanics clearly shows that dynamic properties of soils, including small-strain shear modulus $\left(\mathrm{G}_{\max }\right)$, shear modulus reduction $\left(\mathrm{G} / \mathrm{G}_{\max }\right)$, and damping ratio (D) curves are affected by changes in the soil suction level. The current study present nonlinear time-dependent analysis of three different unsaturated soils available in the literature with different ranges of nonlinear behaviour that earlier have been studied on unsaturated dynamic models. Since, the earthquake intensity parameters can be used to describe the damage potential of an earthquake, the focus of this paper is to evaluate the impact of the suction variation on the engineering ground motion parameters, including peak values of strong motion, Vmax/Amax, rootmean-square acceleration, Arias intensity, characteristic intensity, cumulative absolute velocity, acceleration spectrum intensity, effective design acceleration, A95 parameter and predominant period separately under the near-field and the far-field seismicity categories.
\end{abstract}

\section{Introduction}

Suction affects the behaviour of soil by modifying the skeleton stress through changes in the average fluid pressure acting in the soil pores and providing an additional bonding force at the particle contacts [1], which are a major role in determination of dynamic properties of soil, such as small-strain shear modulus, normalized modulus reduction and damping ratio $\left(\mathrm{G} / \mathrm{G}_{0-}\right.$ $\gamma$ and D- $\gamma$ ) curves. One finds that [2] presents the investigation basis of the linear ground response analysis by considering the mean net stress and suction on the initial shear stiffness $\left(\mathrm{G}_{0}\right)$ and damping ratio $\left(\mathrm{D}_{0}\right)$ of soils with the different plasticity indices. They have discussed the amplification function in terms of the amplification ratio of the surface motion and concluded that the natural frequency of a soil deposit significantly increases with the suction increase and the maximum amplification ratio is substantially reduced. More recently, [3-5] investigated the linear, equivalent linear and nonlinear seismic ground response analysis of several unsaturated soil deposits with considering the suction effects on $\mathrm{G} / \mathrm{G}_{0}-\gamma$ and $\mathrm{D}-\gamma$ curves that demonstrated increasing of suction level led to increasing natural frequency. Also, it was found that the responses of the structures on the unsaturated soil profiles are more severe than the saturated ones, particularly at the higher frequencies. The difference in the dynamic material properties by changing of the suction, consequently distinct the characteristics of output motions in comparison with the input motion (Fig 1). Therefore, representation of the seismic site response of

\footnotetext{
a Mahnoosh Biglari: m.biglari@razi.ac.ir
}

soil deposits with considering the suction would be indispensable where the water table level rises up and falls down extremely. In particular, because of the recent drought, changing of the suction profoundly affects previous calculations of the soil response especially for important structures.

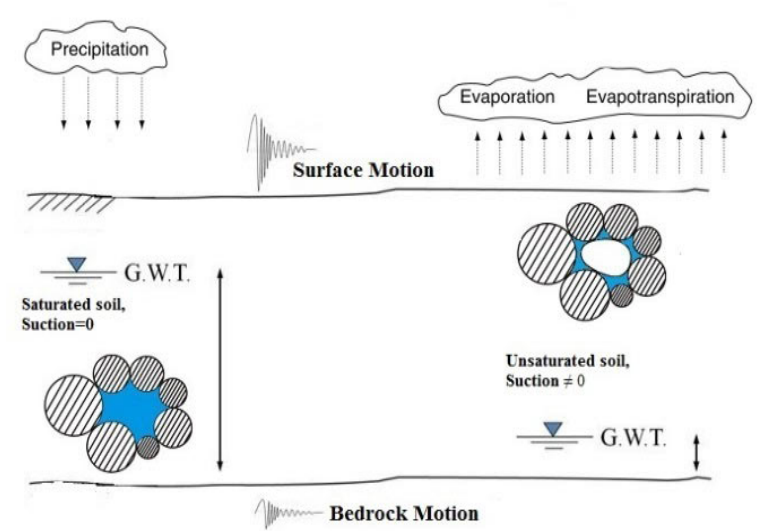

Figure 1. A visualization of differences of the output motion in the saturated and the unsaturated soils.

In this study, three different low plasticity fine grained soils that earlier have been studied on the unsaturated dynamic models are used to produce some various profiles with a variety of suction for analysis of their time domain seismic responses. The paper is studying the 
influence of the suction variation on the seismic ground response analysis and investigates separately the effect of suction in the near field and the far field input earthquake events on strong ground motion parameters with using a computer program of DEEPSOIL.V6 that performs analyses in the frequency (linear and equivalent linear) and in the time (linear and nonlinear) domains.

\section{Material properties}

Three different soils, namely Zenoz kaolin, Completely Decomposed Tuff (CDT) and Po silt chosen for building of soil profiles. Zenoz kaolin as reported by [6] is a commercial Iranian kaolin from a mine in northwest Iran. It is classified as CL according to the Unified Soil Classification System (USCS). Clay and silt fraction of Zenoz kaolin (Zk) is about $18 \%$ and $60 \%$, respectively. CDT as reported by [7] extracted from a deep excavation site in Fanling, Hong Kong can be described as clayey silt (ML) according to the USCS. The material is yellowish-brown, slightly plastic, with a grain size distribution of 24, 74 and 4 for sand, silt and clay, respectively. Po silt (PO) as reported by [8] is a clayey, slightly sandy silt and was extracted from the banks of the Po River (Italy) with a clay fraction of about $27 \%$, and a silt fraction of about $40 \%$. Some of the available information for the physical properties of the mentioned soil samples (i.e. ZK, Po and CDT) summarized in Table1.

Table 1. Index properties of soils used in the definition of dynamic properties of profiles.

\begin{tabular}{c|ccc}
\hline Parameters & Zenoz kaolin & CDT & Po silt \\
\hline Specific gravity & 2.65 & 2.73 & 2.74 \\
Liquid limit(\%) & 29 & 43 & 51 \\
Plastic limit(\%) & 17 & 29 & 33 \\
Plasticity index (\%) & 12 & 14 & 18 \\
Classification (USCS) & CL & ML & ML/MH
\end{tabular}

The study were considered eleven soil profiles (four soil profiles of ZK in the suction levels of 0, 50, 150 and 300 $\mathrm{kPa}$, four soil profiles of CDT in the suction levels of 0 , 50,100 and $200 \mathrm{kPa}$ and three soil profiles of PO in the suction levels of 100,200 and $400 \mathrm{kPa}$ ) with constant suction in depth of the profile. All of the soil profiles have 24 meter depth overlaying the stiff elastic half-space bedrock (of course it should be noted that the bedrock damping ratio has no effect in time domain analyses) with 24 same-thickness sub layers in order to satisfy the propagation condition of highest frequency in the soil layers ( $f_{\max }=V_{s} / 4 H$ ) especially in the stiffer soils.

A plot of the shear modulus $(\mathrm{MPa})$ versus the unit weight $\left(\mathrm{kN} / \mathrm{m}^{3}\right)$ of all of the layers and all of the profiles are displayed (Fig 2). As shown in this figure for soil profiles of CDT and ZK, variation of the shear modulus and the unit weight with the suction has a greater sensitivity rather than PO. Furthermore, there is a huge difference between shear modulus variation and unit weight ranges for PO \& CDT with ZK.

\section{Modelling procedure}

\subsection{Small-strain shear modulus (Gmax)}

To obtain the shear modulus at very small strain, empirical formulation of [1] (Eq. 1) which is based on the framework suggested by [9] is used.

$\mathrm{G}_{0}=\operatorname{Ap}_{\mathrm{atm}}{ }^{1-\mathrm{n}}\left(\mathrm{p}^{\prime \prime}\right)^{\mathrm{n}}\left(\mathrm{OCR}_{\mathrm{p}^{\prime \prime}}\right)^{\mathrm{m}} \mathrm{f}(\mathrm{e}) \mathrm{h}\left(\mathrm{s}_{\mathrm{r}}\right)$

Where $\mathrm{h}\left(\mathrm{s}_{\mathrm{r}}\right)$ is a non-dimensional function as Eq. (2), $\mathrm{f}(\mathrm{e})$ is a void ratio function $\left(\mathrm{f}(\mathrm{e})=\left\{(2.973-\mathrm{e})^{2} /(1+\mathrm{e})\right\}\right)$, OCRP" $_{\mathrm{P}}$ is the overconsolidation ratio and in the normallyconsolidated conditions is equal to $1, \mathrm{P}_{\mathrm{atm}}$ is the atmospheric pressure, $\mathrm{P}^{\prime \prime}$ is the average skeleton stress $\left(p^{\prime \prime}=\left(p-u_{a}\right)+S_{r} \cdot s\right), s$ is suction equal to $\left(u_{a}-u_{w}\right), S_{r}$ is the degree of saturation, $u_{a}$ is the air pressure, $u_{w}$ is the water pressure, $\mathrm{p}$ is the average total stress, $\xi$ is the bonding variable defined as Eq.(3) where $f(s)$ is a function that depends on the size of the particles and the value of the water surface tension. The value of $f(s)$ was considered equal to 1 for the range of suctions in this study.

$$
\begin{aligned}
& \mathrm{h}\left(\mathrm{s}_{\mathrm{r}}\right)=1-\mathrm{a}^{\prime}\left[1-\exp \left(\mathrm{b}^{\prime} \frac{\xi}{\mathrm{f}(\mathrm{s})}\right)\right] \\
& \xi=\mathrm{f}(\mathrm{s})\left(1-\mathrm{S}_{\mathrm{r}}\right)
\end{aligned}
$$

The other model parameter values for CDT and PO were determined according to the previous laboratory research of [10]. Therefore, predicting of the shear modulus at very small strain according to [1] model in variation of suction and mean net stress for PO and CDT such as ZK, which was previously available became possible.

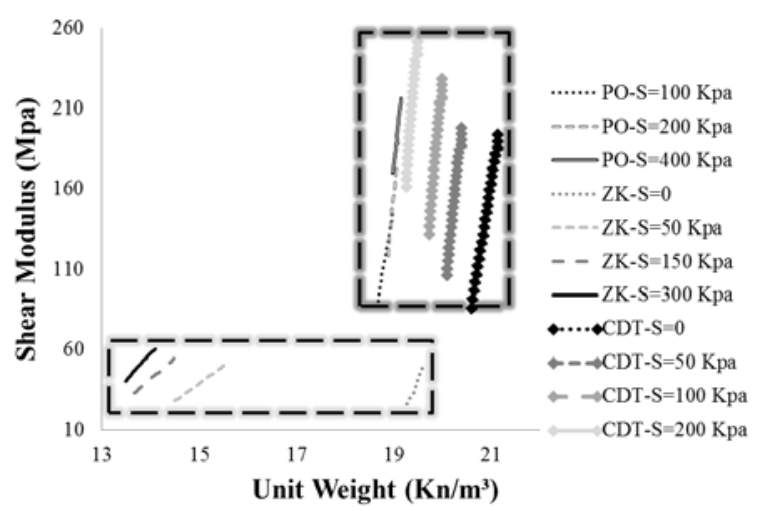

Figure 2. Variation of the unit weight with the suction.

\subsection{Normalized shear modulus and damping ratio curves}

[11] modified the empirical equation proposed by [12] to take into account the influence of the suction level as well as the stress state and the index properties for an unsaturated soils. Equations 4-7 represent the empirical equations for $\mathrm{G} / \mathrm{G}_{0}-\gamma$ and $\mathrm{D}-\gamma$ curves.

$\frac{\mathrm{G}}{\mathrm{G}_{0}}=\mathrm{A}(\gamma, \xi, \mathrm{PI})\left(\frac{\mathrm{p}^{\prime \prime}}{\mathrm{p}_{\mathrm{atm}}}\right)\left(\mathrm{n}(\gamma, \mathrm{PI})-\mathrm{n}_{0}\right)$ 


$$
\begin{aligned}
& \mathrm{A}(\gamma, \xi, \mathrm{PI})=0.5\left[1+\tanh \left\{\ln \left[\frac{0.00005+0.0167 \xi^{12.16}+\mathrm{f}(\mathrm{PI})}{\gamma}\right]^{\left[0.26+3.61 \xi^{11.6}\right]}\right]\right\} \\
& \begin{cases}0 & \text { for } \mathrm{PI}=0 \\
& (\text { sandy soils) }\end{cases}
\end{aligned}
$$

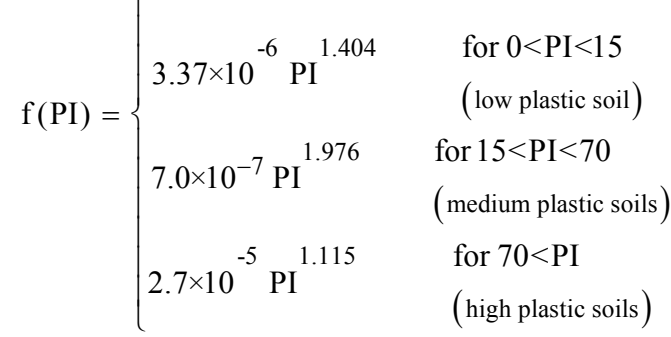

$$
\begin{aligned}
& \mathrm{n}(\gamma, \mathrm{PI})-\mathrm{n}_{0}=0.272\left[1-\tanh \left\{\ln \left[\frac{0.000556}{\gamma}\right]^{0.4}\right\}\right] \mathrm{e}^{\left(-0.0145 \mathrm{PI}^{1.3}\right)} \\
& D=f\left(\frac{G}{G_{0}}\right) A(P I)= \\
& {\left[0.358\left\{-0.11\left(\frac{\mathrm{G}}{\mathrm{G}_{0}}\right)^{2}-0.587\left(\frac{\mathrm{G}}{\mathrm{G}_{0}}\right)+1\right\}\right]\left[\frac{1+\mathrm{e}^{-0.0145 \mathrm{PI}^{1.3}}}{2}\right]}
\end{aligned}
$$

Where $\mathrm{A}(\gamma, \xi, \mathrm{PI})$ is the stiffness index ratio defined as Eq. 5, $\mathrm{n}(\gamma, \mathrm{PI})$ as defined in Eq. 7 , is a stiffness coefficient accounts for the effect of $p^{\prime \prime}$ on the stiffness, $\mathrm{n}_{0}$ is a stiffness coefficient accounts for the effect of $\mathrm{p}^{\prime \prime}$ on the stiffness in the small strain range and PI is the soil plasticity index.

\section{3 fitting process}

In this paper, MRDF model was used for determining the best fit curves of shear modulus and damping ratio. This model proposed a formulation that modifies the loadingunloading criteria that result from using the Masing rules [13]. The new formulation provides better agreement with the damping curves for larger shear strains [14].

\section{Input excitations}

A series of 28 ground motion time history records with considering of near field and far field effects are selected from the pacific earthquake engineering research center database (PEER) as listed in Table 2. The largest horizontal component of each record was used as the input excitation. The ground motions are normalized to a target peak acceleration of $0.1 \mathrm{~g}$ and the baseline correction technique applied for the all of the acceleration time histories. Figure 3 displays the scatter plot of the $M$ (moment magnitude) and $\mathrm{R}$ (rupture distance) of the records.

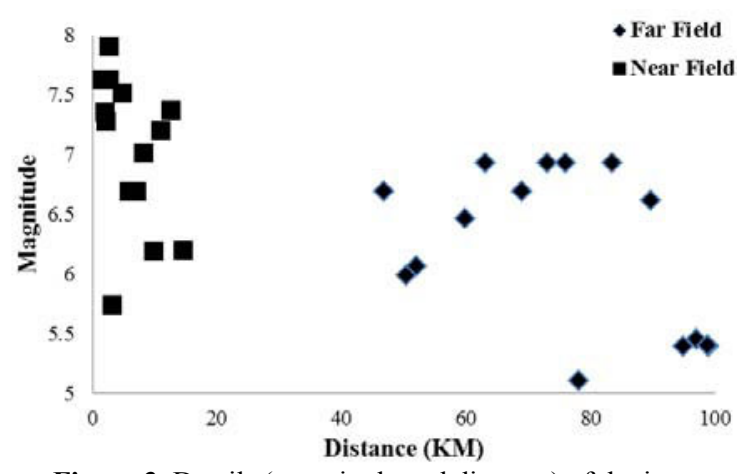

\begin{tabular}{|c|c|c|c|c|}
\hline $\begin{array}{c}\text { Earthquake } \\
\text { Name }\end{array}$ & Year & Station Name & Magnitude & $\begin{array}{l}\text { Rrup } \\
(\mathbf{k m})\end{array}$ \\
\hline Cape Mendocino & 1992 & Petrolia & 7.01 & 8.18 \\
\hline $\begin{array}{c}\text { Chi-Chi, Taiwan- } \\
03\end{array}$ & 1999 & TCU076 & 6.2 & 14.66 \\
\hline Coyote Lake & 1979 & Gilroy Array & 5.74 & 3.11 \\
\hline Denali, Alaska & 2002 & $\begin{array}{l}\text { TAPS Pump } \\
\text { Station }\end{array}$ & 7.9 & 2.74 \\
\hline $\begin{array}{c}\text { El Mayor- } \\
\text { Cucapah, Mexico }\end{array}$ & 2010 & $\begin{array}{c}\text { CERRO } \\
\text { PRIETO } \\
\text { GEOTHERMAL }\end{array}$ & 7.2 & 10.92 \\
\hline Kocaeli, Turkey & 1999 & Yarimca & 7.51 & 4.83 \\
\hline Manjil, Iran & 1990 & Abbar & 7.37 & 12.55 \\
\hline Morgan Hill & 1984 & Gilroy Array & 6.19 & 9.87 \\
\hline Northridge-01 & 1994 & LA Dam & 6.69 & 5.92 \\
\hline Northridge-01 & 1994 & $\begin{array}{l}\text { Pacoima Dam } \\
\text { (downstr) }\end{array}$ & 6.69 & 7.01 \\
\hline Northridge-01 & 1994 & $\begin{array}{l}\text { Pacoima Dam } \\
\text { (upper left) }\end{array}$ & 6.69 & 7.01 \\
\hline Tabas, Iran & 1978 & Tabas & 7.35 & 2.05 \\
\hline Chi-Chi, Taiwan & 1999 & TCU076 & 7.62 & 2.74 \\
\hline Chi-Chi, Taiwan & 1999 & TCU102 & 7.62 & 1.49 \\
\hline 14383980 & 2008 & $\begin{array}{l}\text { Green Oak } \\
\text { Ranch }\end{array}$ & 5.39 & 98.95 \\
\hline 14383980 & 2008 & Antelope & 5.39 & 94.97 \\
\hline Big Bear-01 & 1992 & $\begin{array}{c}\text { Rancho } \\
\text { Cucamonga - } \\
\text { Deer Can }\end{array}$ & 6.46 & 59.87 \\
\hline 40204628 & 2007 & Bolinas & 5.45 & 97 \\
\hline Kozani, Greece-02 & 1995 & Grevena & 5.1 & 78.11 \\
\hline Loma Prieta & 1989 & $\begin{array}{l}\text { Piedmont Jr } \\
\text { High School } \\
\text { Grounds }\end{array}$ & 6.93 & 73 \\
\hline Loma Prieta & 1989 & Point Bonita & 6.93 & 83.45 \\
\hline Loma Prieta & 1989 & $\begin{array}{l}\text { SF - Pacific } \\
\text { Heights }\end{array}$ & 6.93 & 76.05 \\
\hline Loma Prieta & 1989 & $\begin{array}{c}\text { So. San } \\
\text { Francisco, Sierra } \\
\text { Pt. }\end{array}$ & 6.93 & 63.15 \\
\hline N. Palm Springs & 1986 & $\begin{array}{l}\text { Anza - Tule } \\
\text { Canyon }\end{array}$ & 6.06 & 52.06 \\
\hline Northridge-01 & 1994 & Anacapa Island & 6.69 & 68.93 \\
\hline Northridge-01 & 1994 & Antelope Buttes & 6.69 & 46.91 \\
\hline San Fernando & 1971 & $\begin{array}{l}\text { Cedar Springs, } \\
\text { Allen Ranch }\end{array}$ & 6.61 & 89.72 \\
\hline $\begin{array}{l}\text { Whittier Narrows- } \\
01\end{array}$ & 1987 & $\begin{array}{c}\text { Vasquez Rocks } \\
\text { Park }\end{array}$ & 5.99 & 50.39 \\
\hline
\end{tabular}

Figure 3. Details (magnitude and distance) of the input motions.

Table 2. Details of the input motions.

\section{Results}

This study reviews numbers of the earthquake intensity indices in dynamics analysis of the unsaturated sediment, according to the input motions with one-dimensional nonlinear approach. To eliminate the effect of variability 
of the earthquake record and also consider the pure soil deposit effect, the amounts of the indices in any suction level at the surface of the profiles are normalized to the initial value (base of the profile). Then to evaluate the correlation between the existing earthquake intensity indices and the seismic responses of the unsaturated profiles with varying of the suction the mean values of each intensity parameters is calculated separately for the near-field and the far-field input excitation seismicity categories. In order to highlight the influence of the suction on the nonlinear seismic response of soil layers, soil profiles were considered with the different material properties and nonlinearities.

A wide variety of earthquake intensity indices have been presented. Some of them only describe the amplitude of motion and the other ones just interpret frequency content or duration. Also, another type of the indices exists that is influenced by involving of two or three of these important ground motion characteristics. Hereunder, some of the earthquake intensity indices in terms of the amplitude, the frequency content and the combined parameters separately have been defined. And at the end of the brief description of the parameters, the impact of the suction on the index has been evaluated.

\subsection{Amplitude parameters}

Peak ground acceleration (PGA) is one of the important parameter of ground motion and is defined as the absolute maximum amplitude of acceleration time history. Although, PGA is a poor indicator of the measure of damage potential of ground motion; due to its simplicity and compatibility with many seismic codes, PGA is widely used in the engineering applications.

Peak ground velocity (PGV) is the peak value of the velocity time history, which is popularly applied to characterize the damage potential cause of its sensitivity to the intermediate frequencies of a motion. In the Japanese building code, PGV is used as an index in the seismic analysis.

Effective Design Acceleration (EDA) corresponds to the peak acceleration value found after low pass filtering the input time history with a cut-off frequency of $9 \mathrm{~Hz}$ [16]. Since, pulses of high acceleration at the high frequencies almost induce little response, the notion of the effective design acceleration, has been proposed [15].

Mean ratio values of amplitude parameters (PGA, PGV and EDA) for $\mathrm{ZK}$ profiles in any distances from the earthquake source have a direct relation with the suction increasing. This will attract the attentions to the unsaturated soft soil in intermediate to high frequencies. For stiffer soil profiles, namely PO and CDT subjected to far field and near field earthquakes PGV reduced with suction increasing. While, sensitivity of PGA and EDA to suction in these stiff soil profiles in dealing with near or far field events have a completely reverse trend (Figs 49).

\subsection{Frequency content parameters}

$\underline{\mathrm{V}}_{\max } / \mathrm{A}_{\max }$ is an intensity index that involves the peak ground acceleration (PGA) and the peak ground velocity (PGV). Since for a harmonic motion, this ratio is equal to $\mathrm{T} / 2 \pi$. For an earthquake motions, $\mathrm{V}_{\max } / \mathrm{A}_{\max }$ can be interpreted as the period of an equivalent harmonic motion, thus providing an indication of which periods of the ground motion are most significant. Because the peak velocity and the peak acceleration are usually associated with motions of different frequency the ratio is related to the frequency content of the motion [15].

Predominant Period $\left(\mathrm{T}_{\mathrm{p}}\right)$ is the period corresponds to the peak Fourier amplitude. This parameter represents the frequency content of the motion.

The two above-mentioned indices only describe the frequency content of the motion. As shown in figs 4-9 for all of the soil profiles at any suction levels, seismicity categories and the non-linearity domain, the frequency content absolutely increases with the suction increasing even in the soft soil profiles.

\subsection{Combined parameters}

Acceleration Spectrum Intensity (ASI) is defined as the integral of the pseudo acceleration spectral $\left(\mathrm{S}_{\mathrm{a}}\right)$ over the period range of 0.1 to $0.5 \mathrm{Sec}$ [17].

$$
\mathrm{ASI}=\int_{0.1}^{0.5} \mathrm{Sa}(\mathrm{T}, 5 \%) \mathrm{dT}
$$

As seen in the Figures 4-9, the mean ratio of the present index absolutely shows a same general tendency versus the suction variation. The index reflected amplitude and the frequency content of motion in short periods and insistently states potentially dangerous to suction increasing.

Cumulative absolute velocity (CAV) is defined as the integral of the absolute value of ground acceleration over the seismic time-history record [15].

$$
\mathrm{CAV}=\int_{0}^{\mathrm{t}}|\mathrm{a}(\mathrm{t})| \mathrm{dt}
$$

The trend of this index to the suction variation (Figs 4-9) is independent of distance from the earthquake source and only is the function of the dynamic properties of the soil profiles. The soil profiles with more non-linearity (i.e. ZK) in comparison with the stiffer profiles (i.e. PO \& CDT) show a thoroughly opposite trend in the suction variation.

Arias Intensity $\left(\mathrm{I}_{\mathrm{a}}\right)$ is defined by $[18]$ :

$$
\mathrm{I}_{\mathrm{a}}=\frac{\pi}{2 \mathrm{~g}} \int_{0}^{\infty} \mathrm{a}(\mathrm{t})^{2} \mathrm{dt}
$$

Where $I_{a}$ is the Arias Intensity in units of length per time, $a(t)$ is the acceleration-time history and $g$ is gravitational acceleration. Arias Intensity is an earthquake intensity index that correlates with the potential destructiveness of an earthquake.

Root-mean-square acceleration ( $\mathrm{a}_{\mathrm{RMS}}$ ) is a measure of the average rate of energy imparted by the ground motion and is defined as:

${ }^{\mathrm{RMS}}=\sqrt{\frac{1}{\mathrm{t}_{0}^{\mathrm{t}}[\mathrm{a}(\mathrm{t})]^{2} \mathrm{dt}}}$ 
Where $a(t)$ is the acceleration time history and $t$ is the total duration of the ground motion. This parameter is often useful for the engineering purposes because it incorporates the effect of duration and it is not strongly influenced by large, high-frequency accelerations, which typically occur only over a very short period. However, aRMS does not provide any information about the frequency content because it is the sum of the input energy at all frequencies. Obviously, aRMs depends on the method used to define strong-motion duration.

Characteristic intensity $\left(\mathrm{I}_{c}\right)$ proposed [19] and given by

$$
\mathrm{I}_{\mathrm{c}}=\mathrm{a}_{\mathrm{RMS}}^{1.5} \cdot \mathrm{t}_{\mathrm{s}}^{0.5}
$$

Where $t_{s}$ is the significant duration of the ground motion. Significant duration, $t_{s}$, is defined by [20] as the interval between the times at which $5 \%$ and $95 \%$ of the Arias intensity is attained. The proposed intensity index has proven to correlate well with the damage potential and can be considered a reasonable representation of the destructive ground motions.

A95 parameter is another earthquake intensity index that was proposed by [21] and is the maximum value of the acceleration that corresponds to $95 \%$ of the Arias Intensity value. However, this index being less popular among the researchers, A95 such as the Arias Intensity summarizes the ground motion parameters included in amplitude, frequency content and duration in a single parameter. Four above-mentioned parameters (i.e. $I_{a}$, $\mathrm{a}_{\mathrm{RMS}}, \mathrm{I}_{\mathrm{c}}$ and A95) have a close relationship together. So, it is expected that the parameters have a same tendency to the suction variation. As shown in the Figures 4-9 variation of the mean ratios of these parameters verify aforesaid statement. The tendency of these indices to the suction is sensitive to the both soil non-linearity and the distance from event source. Interpretation of the following plotted data about the indices revealed that, in the soft soil profiles (i.e. ZK) with any distance from the source, increasing in suction leads to increasing in damage potential. Also, for more dense profiles (i.e. PO \& CDT), subjected to the far Field earthquakes this relationship is established.

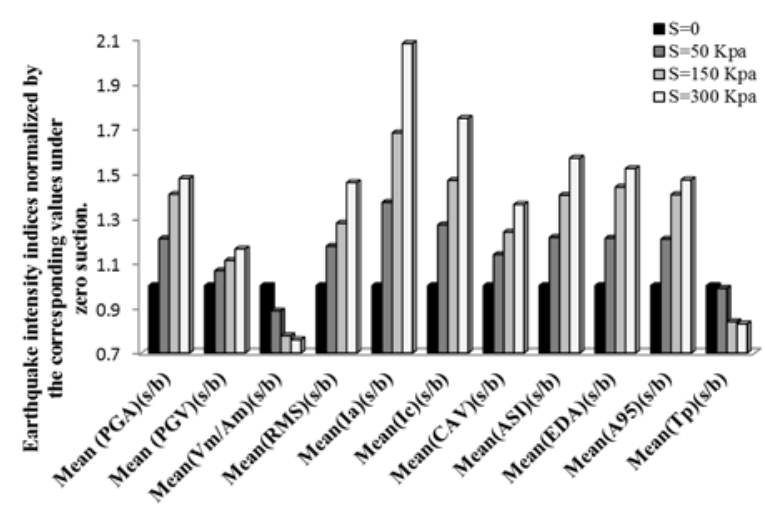

Figure 4. Normalized mean intensity indices ratios of surface (s) of ZK profiles to bedrock (b) under far field events.

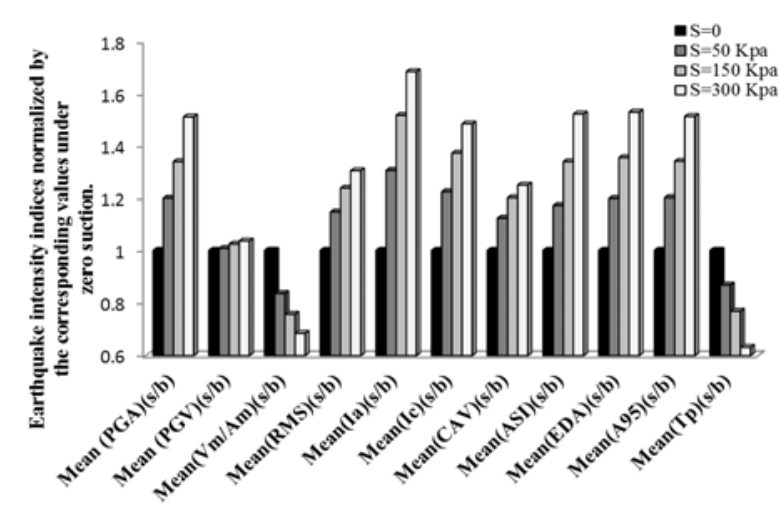

Figure 5. Normalized mean intensity indices ratios of surface (s) of ZK profiles to bedrock (b) under near field events.

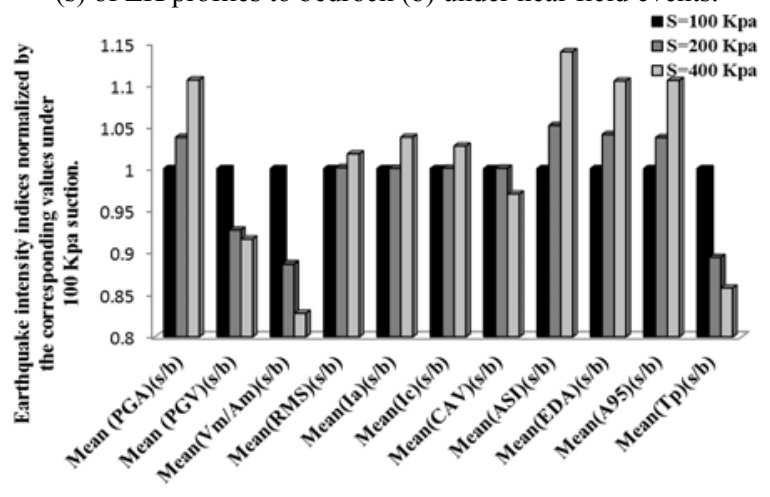

Figure 6. Normalized mean intensity indices ratios of surface (s) of PO profiles to bedrock (b) under far field events.

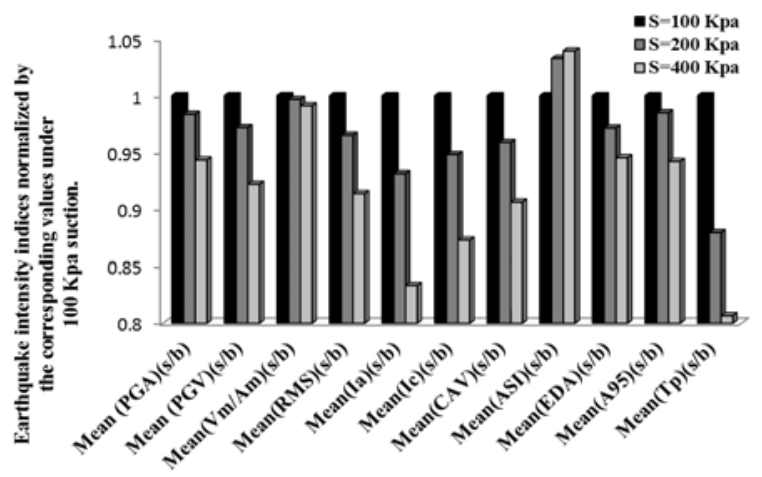

Figure 7. Normalized mean intensity indices ratios of surface (s) of PO profiles to bedrock (b) under near field events.

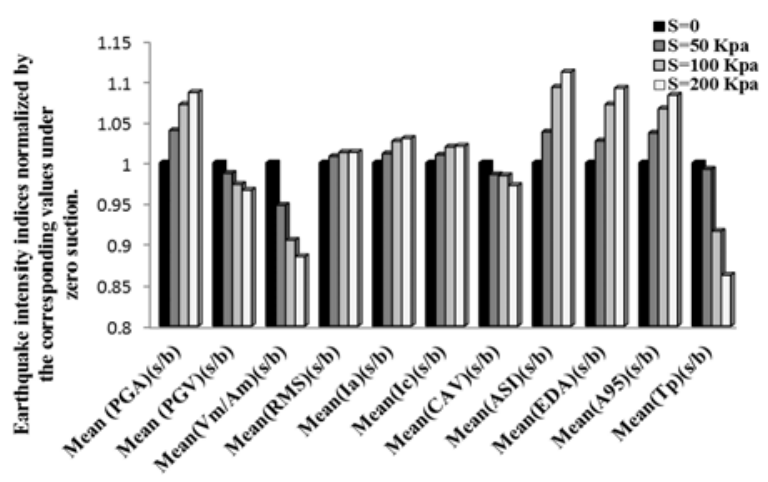

Figure 8. Normalized mean intensity indices ratios of surface (s) of CDT profiles to bedrock (b) under far field events. 


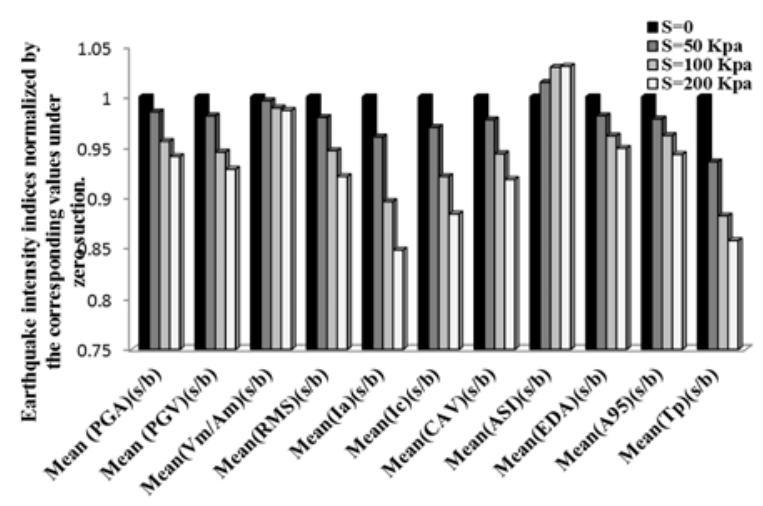

Figure 9. Normalized mean intensity indices ratios of surface (s) of CDT profiles to bedrock (b) under near field events.

\section{Conclusions}

In the present paper, the nonlinear site response analyses were performed for three unsaturated soil samples with varying of the suction and the different mechanical and physical properties. To avoid the interference of the different distance from the epicenter to the analyzed results, 28 near field and far field ground motions are selected. In order to emphasize on the influence of the suction variation on the characteristics of strong ground motion, a series of earthquake intensity indices, which capture the effects of amplitude, frequency content and duration of a ground motion record was investigated. The results are plotted separately as the mean ratio of each earthquake intensity index on the top to the bottom of the soil profiles at each suction level for the near field and the far field input motions. Finally, to clearly show differences at each suction level, the mean ratios are normalized to the corresponding values at the minimum suction. Response of the different soil samples (i.e. ZK, Po and CDT) shows that the dynamic response of soils in addition of the suction, is extremely affected by the important parameters in determining of the soil nonlinearity such as, plastic index, void ratio and mean net stress. Hence, some conclusions are listed below from the analysis results of the suction variation versus the earthquake intensity indices.

- In the softer profiles (i.e. ZK), the higher suction levels definitely increase damage potential of the ground motion. Also, the tendency of the suction variation to the earthquake intensity indices has no correlation with the distance from the epicentre.

- Two indices that $\left(\mathrm{V}_{\max } / \mathrm{A}_{\max }\right.$ and Predominant Period) only describe the frequency content of the motion indicates that for all of the soil profiles at any suction levels, seismicity categories and the non-linearity domain, the frequency content absolutely increases with the suction increasing even in the soft soil profiles.

- The other indices that indicate damage potential of earthquake, for CDT and PO revealed the opposite trend subjected to near field and far field. So that, potential danger of the suction increasing in the far field earthquakes, in spite of the near field ground motion will be increasing. It should be noted that for these dense soils, PGV decreased with the suction increasing in any distance from epicenter. Since, the velocity is to characterize ground motion amplitude at intermediate frequency for structures that are sensitive to loading in intermediate frequency range, suction increasing reduced potential for damage.

\section{References}

[1] M. Biglari, C. Mancuso, A. d'Onofrio, M.K. Jafari, A. Shafiee, Comp. and Geotech., 38(5), 709-720, (2011).

[2] F. d'Onza, A. d'Onofrio, C. Mancuso, $1^{\text {st }}$ European Conf on Unsat. Soils, 531-536, (2008).

[3] M. Biglari, I. Ashayeri, Inter. Jour. of Civil Eng., 11(2), 150-155, (2013).

[4] M. Biglari, I. Ashayeri, F. Fouladi $6^{\text {th }}$ Inter. Conf. on Unsat. Soils, 389-396, (2014).

[5] F. Fouladi, M. Biglari, I. Ashayeri, $7^{\text {th }}$ Inter. Conf. on Seismology and Earthquake Eng., (2015).

[6] M. Biglari, A. d'Onofrio, C. Mancuso, M.K. Jafari, Can Geotech J, 49(3), 311-322, (2012).

[7] C.W.W. Ng, S.Y. Yung, Géotech., 58(1), 23-35, (2008).

[8] R. Vassallo, C. Mancuso, F. Vinale, Can. Geotech. J, 44(4), 447-462, (2007).

[9] D. Gallipoli, A. Gens, R. Sharma \& J. Vaunat, Géotech., 53 (1), 123-135, (2003).

[10] K.S. Wong, D. Mašín, C.W.W. Ng, Comp. and Geotech., 56, 28-39, (2014).

[11] M. Biglari, I. Ashayeri, 5th Asia-Pacific Conf on Unsat. Soils, 591-596, (2012).

[12] I. Ishibashi, X. Zhang, Soil and Found., 33(1), 182191, (1993).

[13] G. Masing, $2^{\text {nd }}$ Int Congress on App. Mech., 332335, (1926).

[14] C. Phillips, Y.M.A. Hashash, Soil Dyn. and Earth. Eng., 29(7), 1143-1158, (2009).

[15] S.L. Kramer, Geotechnical earthquake engineering, Prentice Hall, Upper Saddle River, New Jersey, (1996).

[16] JR. Benjamin. EPRI Report NP-5930, Electric Power Research Institute, Palo Alto, California, (1988).

[17] J. L. Von Thun, L. H. Rochim, G. A. Scott, and J.A. Wilson, ASCE, New York, 463-481, (1988).

[18] A. Arias, Massachusetts Inst. of Tech., Cambridge. Univ. of Chile, Santiago de Chile, 438-483, (1970).

[19] Y.J. Park, A.H.S. Ang, Y.K. Wen. Jour. of Struct. Eng., ASCE 111(4), 740-757, (1985).

[20] M. D. Trifunac and A. G. Brady., Bull. of the Seismo. Society of America, 65(3), 581-626, (1975).

[21] S.K. Sarma, K.S. Yang. Earth. Eng. and Struct. Dyn., 15(1), 119-132, (1987). 